\title{
The Occurrence and Speciation of Hookworms Among Residents Of An Urban Community In Calabar South Local Government Area Of Cross River State, Nigeria.
}

\author{
1,Akpan, S. S. and Agida, R. S.

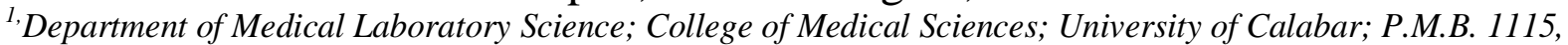 \\ Calabar-Nigeria.
}

\begin{abstract}
The occurrence of hookworms was studied among residents of Bayside in Calabar South from April to July, 2012. A total of 450 volunteers with an age range of 1 to 40 years participated in the study, from whom fresh stool samples were collected for microscopy. The overall prevalence of hookworm infections was 3.3\% (15 $\checkmark 450)$, with Necator americanus as the only species. Females were more infected with hookworms (1.7\%) than males (1.5\%). There was no statistically significant difference in the occurrence of hookworms among male and female subjects $\left(x^{2}=4.012 ; P>0.05\right)$. Eggs of hookworm were cultured for 10 days using the Harada - Mori technique. Only filariform larvae of $N$. americanus were detected and identified using morphologic characteristics. Apart from hookworms, Ascaris lumbricoides (18.7\%) and Trichuris trichiura (1.3\%) were also detected. This study has established a low association of N. americanus with A. lumbricoides and T. trichiura as sympatric parasites within the study area.
\end{abstract}

Keywords: Hookworms, Occurrence, Speciation.

\section{INTRODUCTION}

Two species of hookworm infect human, viz.: Ancylostoma duodenale and Necator americanus. Man becomes infected via cutaneous penetration of the filariform larvae. But A. duodenale can also be acquired through ingestion of fruits and vegetables previously contaminated with human faeces. Human hookworm infections are common in many regions of the world including, but not restricted to, Southern Europe, North Africa, India, China, Southeast Asia, some areas of The United States, The Caribbean and South America (Schmidt et al., 2010). Many people are infected with hookworms without exhibiting symptoms of disease. A heavy hookworm infection in human is associated with many pathologic effects, including anaemia, protein deficiency, heart failure, delayed puberty, mental dullness, etc. Generally, hookworm disease is exhibited in cutaneous, pulmonary and intestinal phases (Schmidt et al., 2010). Zoophilic hookworms such as A. braziliense and A. caninum are natural parasites of cats, dogs and other wild and domestic animals. They occasionally penetrate human, causing vague infections as well as cutaneous larva migrans.Grouping the two genera of human hookworms together is not beneficial during chemotherapy. The practice often leads to treatment failures and rapid rates of re-infection after therapy. Therefore, knowledge of the predominant species in a particular population is essential for a long term success in chemotherapy. There are established morphological differences between adult A. duodenale and N. americanus (Yoshida et al., 1974 a, b; Pawloski et al., 1991). But adult hookworms are rarely recovered for routine parasitological investigations. Therefore, species identification is routinely done using subtle morphologic features to differentiate infective filariform larvae cultured from hookworm eggs detected in human faeces (WHO, 1981; Pawloski et al., 1991).

\section{MATERIALS AND METHODS}

The study area and population

Bayside is a small Urban Community in Calabar South Local Government Area of Cross River State, Nigeria. It is a coastal area located near the bank of Cross River. The local dwellers are predominantly fishermen and traders. Farming is mostly subsistent, with waterleaf, cassava, cocoyam and plantain as the major crops. Housing facilities are basic. There is electricity, but potable water and decent toilet facilities are lacking in the area. 


\section{Collection of stool specimens}

Fresh stool specimens were collected from 450 volunteers after proper enlightenment. The stool samples were collected into dry, clean, transparent, screw-cap universal bottles. The specimens were processed on the same day of collection at the Parasitology Laboratory of the University of Calabar Teaching Hospital.

\section{Macroscopy} adult worms.

Stool samples were examined visually, within transparent containers for consistency, blood, mucus or

\section{Microscopy}

A pea-size quantity of formed stool specimen was placed in a clean universal bottle and homogenized with few drops of normal saline. Direct saline and iodine smears were made on clean slides and examined with 10x and 40x objective lenses for parasites. Formol-ether sedimentation technique was employed to concentrate all the stool specimens.

\section{Culture of hookworm larvae}

Stool samples previously confirmed by microscopy to carry eggs of hookworm, were cultured to recover larvae using the Harada - Mori technique (Rai et al., 1997). Briefly, $5 \mathrm{ml}$ of distilled water was placed in $15 \mathrm{~cm}$ long test tubes and placed in a rack. A smear of faeces, about $5 \mathrm{~cm}$ wide, was made in the middle of a filter paper, measuring $15 \mathrm{~cm}$ in length and $1.0 \mathrm{~cm}$ in breadth. The free end of the filter paper dipped in the water within the test tube. Each test tube was covered loosely with cotton wool to permit aeration. The preparation was incubated on the laboratory bench at room temperature $\left(28\right.$ to $\left.30^{\circ} \mathrm{C}\right)$ for 10 days. Using a pair of forceps, the cotton wool plugs were removed and discarded into a general disposable bin. Test tubes were placed in a water bath at $55^{\circ} \mathrm{C}$ for 15 minutes to immobilize the larvae but preserve their morphologic features. When cool, contents of the test tubes were placed in centrifuge tubes and spun at low speed (1,000 r.p.m.) for 5 minutes. The supernatant was discarded and smears were made with the deposit on clean slides. Morphologic details of the larvae were studied using 40x objective lens. Filariform larvae of A. duodenale and N. americanus are characterized by a blunt head and tail and there is no gap between the oesophagus and intestine. Whereas the oesophagus of the larvae of $A$. duodenale does not end in a thistle funnel shape, that of the larvae of $N$. americanus ends in a thistle funnel shape. This is the main feature which is used to differentiate between the two species (Okolie, 2007).

Statistical analysis: The results obtained were subjected to Chi-Square analysis.

\section{RESULTS}

Stool samples were collected from a total of 450 subjects, aged between 1 and 40 years. Two hundred and forty nine of the subjects were female $(55.3 \%)$, while 201 were male $(44.7 \%)$. Eggs of hookworms were detected in 15 stool specimens. This shows an overall hookworm infection rate of $3.3 \%$ (15 v 450). The overall prevalence of Ascaris lumbricoides and Trichuris trichuira was $18.7 \%$ and 1.3\%, respectively. Table 1 shows the distribution of intestinal helminths according to age groups.

Table 1: The distribution of intestinal helminths according to age groups.

\begin{tabular}{lccccccc}
\hline Age (years) & $\begin{array}{c}\text { Less than 1 } \\
\mathbf{n}=\mathbf{1 8}\end{array}$ & $\begin{array}{c}\mathbf{1 - 1 0} \\
\mathbf{n = 1 7 4}\end{array}$ & $\begin{array}{c}\mathbf{1 1 - 2 0} \\
\mathbf{n = 4 5}\end{array}$ & $\begin{array}{c}\mathbf{2 1 - 3 0} \\
\mathbf{n = 1 1 4}\end{array}$ & $\begin{array}{c}\mathbf{3 1 - 4 0} \\
\mathbf{n = 9 9}\end{array}$ & $\begin{array}{c}\text { Total } \\
\mathbf{4 5 0}\end{array}$ & $\begin{array}{c}\text { Prevale } \\
\text { nce } \\
(\boldsymbol{\%})\end{array}$ \\
\hline PARASITES & NUMBER & OF & CASES & & & & \\
\hline Hookworm & - & & & & & & \\
$\begin{array}{l}\text { T. trichiura } \\
\text { A. lumbricoides }\end{array}$ & - & $3(0.7 \%)$ & $3(0.7 \%)$ & - & - & 6 & 1.3 \\
Total & - & $54(12 \%)$ & $6(1.3 \%)$ & $18(4.0 \%)$ & $6(1.3 \%)$ & 84 & 18.7 \\
\hline
\end{tabular}

The table shows that the percentage of hookworm infection was 2.0 percent among the 1-10 years age group and 1.3 percent among the 11-20 years age group. The prevalence of Trichuris trichiura was 0.7 percent among the 1-10 and 11-20 years age groups. Ascaris lumbricoides was the most predominant parasite with prevalence of $12.0 \%, 1.3 \%, 4.0 \%$ and $1.3 \%$ within $1-10,11-20,21-30$ and $31-40$ age groups, respectively.

Table 2 shows the distribution of intestinal helminthes according to gender. Forty two males and 63 females harboured intestinal helminthes, representing an overall helminth prevalence of $23.3 \%$ (105 v 450). Females were more infected $(13.9 \%)$ than males $(9.3 \%)$. Ascaris lumbricoides was more common among the females $(11.3 \%)$ than males $(7.3 \%)$. 
Table 2: The distribution of intestinal helminthes according to gender

\begin{tabular}{|c|c|c|c|c|}
\hline \multirow{2}{*}{$\begin{array}{l}\text { Gender } \\
\text { Helminth }\end{array}$} & \multicolumn{2}{|c|}{ Male $(n=180)$} & \multicolumn{2}{|c|}{ Female $(n=270)$} \\
\hline & $\begin{array}{l}\text { Number } \\
\text { infected }\end{array}$ & $\begin{array}{r}\text { prevalence } \\
(\%)\end{array}$ & Number infected & $\begin{array}{r}\text { prevalence } \\
(\%)\end{array}$ \\
\hline A. lumbricoides & 33 & 7.3 & 51 & 11.3 \\
\hline Hookworm & 7 & 1.6 & 8 & 1.7 \\
\hline T. trichiura & 2 & 0.4 & 4 & 0.9 \\
\hline Total & 42 & 9.3 & 63 & 13.9 \\
\hline
\end{tabular}

\section{Discussion And Conclusion}

This study has established a low prevalence of hookworm infection among some residents of Bayside in Calabar South. A prevalence of 3.3\% for hookworm infection in this locality is lower than the $68.2 \%$ rate reported by Adenusi and Ogunyomi (2003) in Ibadan, Nigeria. It is also lower than the 23.3\% and 13.3\% prevalence rates reported by Okolie (2007) for hookworm infections in Owerri and Port Harcourt, respectively. Necator americanus was the only species cultured from all the hookworm-positive stool specimens. This finding confirms previous reports that this parasite in the ubiquitous and dominant hookworm species prevalent in different parts of Nigeria (Fisk, 1939; Cowper and Woodward, 1961; Oyerinde, 1978; Adenusi, 1997).Infections with Ascaris lumbricoides, Hookworm and Trichuris trichiura were highest (14.7\%) among the 1-10 years age group (Table 1). This finding confirms that these parasites are common geo-helminthes, which are easily transmitted to children due, especially, to their habits of geophagy and playing about barefoot. None of the volunteers complained of abdominal discomfort at the time of sample collection. Helminth eggs were generally too scanty to permit worm burden estimation. There was no statistically significant difference in the occurrence of intestinal helminthes among males and females $\left(\mathrm{X}^{2}=4.012>3.841 ; \mathrm{P}>0.05\right)$. This finding suggests that gender did not influence the transmission of the helminthes among the subjects. The absence of intestinal protozoa and the presence of relatively light helminth infections in this study have revealed the gains so far recorded in environmental sanitation in Cross River State, especially in Calabar Metropolis. A combination of environmental sanitation, personal hygiene and health education will help to further curb the transmission of microbial infections in the study area.

\section{ACKNOWLEDGEMENTS}

We, hereby, acknowledge the efforts of Mr. Andy Akpan and the entire members of Staff of Akpan Computers, NASU Business Centre, University of Calabar, for typesetting this work.

\section{REFERENCES}

[1]. Adenusi, A. A. (1997). The distribution of Necator americanus and Ancylostoma duodenale among school children in Lagos, Nigeria. Transboundary Royal Society of Tropical Medicine and Hygiene 91 (3): 270.

[2]. Adenusi, A. A. and Ogunyomi, E. O. A. (2003). Relative prevalence of the human hookworm species, Necator americanus and Ancylostoma duodenale in an urban community in Ogun State, Nigeria. African Journal of Biotechnology 2 (11): 470 - 473.

[3]. Cowper, S. G and Woodward, S. F. (1961). Parasitic infections recorded at University College Hospital, Ibadan, Nigeria, over a three year period (1957-1960). West African Medical Journal 10 :366-383.

[4]. Fisk, G. H. (1939). Helminthiasis in Lagos, Nigeria. Transboundary Royal Society of Tropical Medicine and Hygiene 32 : 645-652.

[5]. Okolie, N. J. C, (2007). Application of Harada - Mori's culture method for differentiating hookworm species in two major cities in South Eastern Nigeria. Research Journal of Medical Science 1 (1) : 16 - 20.

[6]. Oyerinde, J. P. O. (1978). Human Ancylostoma infections in Nigeria. Annals of Tropical Medicine and Parasitology 72 (4) : $363-$ 367.

[7]. Pawloski, Z. S., Schad, G. A. and Stott, G. J.(1991). Hookworm infection and anaemia: approaches to prevention and control. World Health Organization, Geneva: 96.

[8]. Rai, S. K., Shrestha, H. G., Nakanishi, M., Kubo, T., Ono, K., Uga, S and Matsumura, T. (1997). Hookworm infections recorded at University Teaching Hospital in Kathmandu, Nepal over one decade period. Japanese Journal of Tropical Medicine and Hygiene $25: 81-84$.

[9]. Schmidt, G. D., Roberts L. S. and Janovy, J. (jnr.) (2010). Hookworm disease. In: Foundations of Parasitology: $423-426$.

[10]. World Health Organization (1981). Intestinal protozoan and helminthic infections. World Health Organization Technical Report Series 666, Geneva.

[11]. Yoshida, Y., Matsuo, K., Kondo, K., Arizona, N. and Ogino, K, (1974a). Scanning electron microscopy of hookworms 2. Adults and infective stage larvae of Necator americanus (Stiles, 1902). South East Asian Journal of Tropical Medicine and Public Health 5 : $510-514$

[12]. ___ (1974b). Scanning electron microscopy of hookworms 2. Adults and infective stage larvae of Ancylostoma duodenale (Dubini 1843). South East Asian Journal of Tropical Medicine and Public Health 5 :515-519. 